\title{
Transduction of Fimbriation Demonstrating Common Ancestry in FIRN Strains of Salmonella typhimurium
}

\author{
By D. C. OLD AND J. P. DUGUID \\ Bacteriology Department, University of Dundee Medical School, \\ Ninewells Hospital, Dundee DD1 9SY, Scotland
}

(Received 11 September 1978; revised 27 November 1978)

\begin{abstract}
The production of fimbriate $\left(\mathrm{Fim}^{+}\right)$recombinants was observed in transductional crosses between different pairs of wild-type strains of different biotypes of Salmonella typhimurium. $\mathrm{Fim}^{+}$recombinants were readily produced in transductions from $\mathrm{Fim}^{+}$donor strains to Fim $^{-}$recipient strains and, less frequently, between some pairs of Fim- strains, for example, between almost any strain of the FIRN biogroup (Fim ${ }^{-}$Inl- $^{-} \mathrm{Rha}^{-} \mathrm{Bxyl}^{-}$) and many strains of the non-FIRN Fim- biogroup. None of numerous crosses between different pairs of FIRN strains gave $\mathrm{Fim}^{+}$recombinants, suggesting that the fim mutation was present at the same intragenic site in all FIRN strains. FIRN strains are thought to have descended from a single ancestral FIRN bacterium which originated by a series of mutations from a strain of the common biotype 1a (Fim $\left.{ }^{+} \mathrm{Inl}^{+} \mathrm{Rha}^{+} \mathrm{Bxyl}^{+}\right)$. Two FIRN-like (Fim- Inl ${ }^{+} \mathrm{Rha}^{-} \mathrm{Bxyl}^{-}$) strains that did not yield Fim ${ }^{+}$recombinants in crosses with FIRN strains were probably wild-type Inl $^{+}$mutants from FIRN strains.
\end{abstract}

\section{INTRODUCTION}

Most wild-type strains of Salmonella typhimurium form type-1 fimbriae, the filamentous appendages that confer mannose-sensitive haemagglutinating properties on bacteria (Duguid et al., 1966). In this serotype, the possession of the fimbriation character $\left(\mathrm{Fim}^{+}\right)$ was associated with that of the ability to ferment inositol $\left(\mathrm{Inl}{ }^{+}\right)$and/or rhamnose $\left(\mathrm{Rha}^{+}\right)$ in peptone water within $24 \mathrm{~h}$ at $37^{\circ} \mathrm{C}$. The association was confirmed by Duguid et al. (1975) in 2030 strains from a variety of sources in 54 countries, including representatives of 19 primary and 144 full biotypes; 275 strains of a Fim- Inl- Rha- (FIRN) biogroup (Morgenroth \& Duguid, 1968), all of which were also Bitter's xylose negative $\left(\mathrm{Bxyl}^{-}\right)$, belonged to the primary biotypes 29 to 32 .

None of the FIRN strains gave spontaneous Fim ${ }^{+}$mutants on serial culture in aerobic static broth; all gave $\mathrm{Rha}^{+}$mutants, but only by the two-step procedure described by Morgenroth \& Duguid (1968); and none readily gave Inl $^{+}$mutants on prolonged culture at $37^{\circ} \mathrm{C}$ in inositol peptone water (Duguid et al., 1975). Thus, all FIRN strains were alike in the behaviour of their fim, inl and rha mutations.

Following preliminary observations by Duguid et al. (1962), we now describe transduction studies which suggest that the site of the fim mutation is the same in all FIRN strains and is different from that in many Fim- ${ }^{-}$strains not of the FIRN group. The principle of these studies, which were made on naturally occurring mutant strains, was derived from the observations of Demerec et al. (1954) and Hartman (1956) on laboratory mutants. They found that mutations produced independently in the same gene generally gave rise to non-identical alleles, and that phenotypically similar mutants with non-identical alleles were usually distinguishable from one another because they gave wild-type recombinants when crossed by transduction. Thus, the absence of recombination between two mutant 
Table 1. Biogroup, phage type/biotype and source of strains of Salmonella typhimurium most commonly tested as donors of fim

\begin{tabular}{|c|c|c|c|}
\hline Biogroup & $\begin{array}{l}\text { Strain } \\
\text { no. }\end{array}$ & $\begin{array}{c}\text { Phage type/ } \\
\text { biotype }\end{array}$ & Source or derivation \\
\hline $\mathrm{Fim}^{+}$ & $\begin{array}{l}\text { LT2 } \\
\text { LT2-497 } \\
\text { S844 } \\
\text { S375 } \\
\text { S12 } \\
\text { S1404 } \\
\text { S745 }\end{array}$ & $\begin{array}{c}4 / 1 \mathrm{f} \\
4 / 1 \mathrm{y} \\
1 / 1 \mathrm{a} \\
1 / 3 \mathrm{a} \\
135 / 25 \mathrm{f} \\
44 / 26 \mathrm{i} \\
49 / 26 \mathrm{y}\end{array}$ & $\begin{array}{l}\text { Lilleengen's (1948) type-2 strain } \\
\text { Mutant from strain LT2 } \\
\text { Man, Malawi, 1960 } \\
\text { Boyd's (1956) strain Q1 } \\
\text { Man, Scotland, 1955 } \\
\text { Guinea-pig, England, } 1961 \\
\text { Lilleengen's (1948) type-9 strain }\end{array}$ \\
\hline FIRN & $\begin{array}{l}\text { S1577 } \\
\text { S635 } \\
\text { S580 } \\
\text { S2599 } \\
\text { S2584 } \\
\text { S2266 } \\
\text { S1298 } \\
\text { S7471 } \\
\text { S1290 } \\
\text { S2322 } \\
\text { S654 } \\
\text { S706 } \\
\text { S2716 } \\
\text { S735 } \\
\text { S3381 } \\
\text { S704 }\end{array}$ & $\begin{array}{l}13 / 29 \mathrm{~b} \\
13 / 29 \mathrm{bc} \\
13 / 29 \mathrm{bcf} \\
13 / 29 \mathrm{bf} \\
40 / 29 \mathrm{bf} \\
80 / 30 \mathrm{by} \\
1 / 31 \mathrm{~b} \\
1 / 31 \mathrm{~b} \\
13 / 31 \mathrm{~b} \\
40 / 31 \mathrm{~b} \\
92 / 31 \mathrm{~b} \\
58 / 31 \mathrm{bg} \\
13 / 31 \mathrm{bgz} \\
1 / 32 \mathrm{~b} \\
161 / 32 \mathrm{~b} \\
80 / 32 \mathrm{bf}\end{array}$ & $\begin{array}{l}\text { Man, Maine, U.S.A., } 1962 \\
\text { Fowl, Scotland, 1959 } \\
\text { Man, U.S.A., Friewer \& Leifson (1952) } \\
\text { Man, Egypt, 1959 } \\
\text { Bone, India, 1963 } \\
\text { Cattle, England, } 1963 \\
\text { Man, England, } 1962 \\
\text { Man, England, } 1958 \\
\text { Fowl, Scotland, 1962 } \\
\text { Turkey, England, 1963 } \\
\text { Chinchilla, England, } 1958 \\
\text { Guinea-pig, Sweden, } 1959 \\
\text { Man, England, 1959 } \\
\text { Lilleengen's (1948) type-1 strain } \\
\text { Man, England, 1967 } \\
\text { Parrot, Sweden, 1959 }\end{array}$ \\
\hline Non-FIRN Fim ${ }^{-}$ & \multicolumn{3}{|c|}{ See ${ }^{*}$ strains, Table 2} \\
\hline FIRN-like & $\begin{array}{l}\text { S2338 } \\
\text { S6925 }\end{array}$ & $\begin{array}{l}160 / 21 \mathrm{~b} \\
13 / 23 \mathrm{by}\end{array}$ & $\begin{array}{l}\text { Man, England, } 1963 \\
\text { Dog, Scotland, } 1958\end{array}$ \\
\hline Induced Fim ${ }^{-}$mutant & $\begin{array}{l}\text { LT2-D46 } \\
\text { LT2-D46 }\end{array}$ & $\begin{array}{l}36 / 7 \mathrm{bcz} \\
36 / 7 \mathrm{bcz}\end{array}$ & $\begin{array}{l}\text { Mutant from strain LT2 } \\
\text { Mutant from strain LT2 }\end{array}$ \\
\hline
\end{tabular}

strains suggests that they have descended from the same mutant bacterium and not from separately produced mutants.

The gene determining the production of type-1 fimbriae in $S$. typhimurium is located on the chromosome at map position 23 min (see Sanderson, 1972) and is transmissible by transduction with phage P22 (Old \& Duguid, 1971). The fimbriate transductants are readily selected from motile recipients by culture of the transduction mixture in aerobic static broth, where aerotactic migration combined with the ability of fimbriate bacteria to grow in a surface pellicle with access to atmospheric oxygen enables the Fim ${ }^{+}$transductants to outgrow the parental Fim- bacteria confined within the broth (Old \& Duguid, 1970).

\section{METHODS}

Bacteria. We tested 320 of the wild-type strains of S. typhimurium biotyped by Duguid et al. (1975) and 4 variants from them. Most of the wild-type strains had been isolated from widely separate sources and epidemic foci. Their 'definitive phage types' (Anderson et al., 1977) were determined at the Enteric Reference Laboratory, Public Health Laboratory Service, London. They were classified by their Fim, Inl and Rha characters into four 'biogroups'.

(i) $\mathrm{Fim}^{+}$biogroup. These were 21 wild-type strains isolated from man and five animal species in seven countries between 1940 and 1963. They represented 14 different full biotypes and 12 different phage types. Strain LT2-497, supplied by Professor B. A. D. Stocker, was a streptomycin-resistant, cysteine-requiring laboratory mutant from strain LT2 (Table 1) and was wild-type in its Fim ${ }^{+}$character. The results of tests in which it was used as a donor have been aggregated with those of the 21 wild-type Fim ${ }^{+}$strains.

(ii) FIRN biogroup. These were 258 of the 275 wild-type FIRN strains of Duguid et al. (1975). The 4 phage-untypable and 13 of the 16 non-motile strains in the series of 275 were not tested because it is difficult 
Table 2. Phage type/biotype, source, and place and date of isolation of non-fimbriate strains of Salmonella typhimurium in generally fimbriate biotypes (non-FIRN Fimbiogroup)

\begin{tabular}{|c|c|c|c|c|}
\hline $\begin{array}{l}\text { Strain } \\
\text { no.* }\end{array}$ & $\begin{array}{c}\text { Phage type/ } \\
\text { biotype }\end{array}$ & Source & Place & Date \\
\hline S2365 & $19 / 1 b$ & Drain & Wales & 1964 \\
\hline S2231* & $25 / 1 b$ & Fowl's egg & Argentina & 1962 \\
\hline S519* & $69 / 1 b c$ & Man & England & 1934 \\
\hline S2787 & $5 / 1$ bf & Mouse & Tennessee, U.S.A. & 1962 \\
\hline S3476 & $29 / 1$ bf & Man & Scotland & 1971 \\
\hline S3477 & $29 / 1$ bf & Man & Scotland & 1971 \\
\hline S3146 & $12 / 3 b$ & Man & Mexico & 1969 \\
\hline $\mathrm{S} 2506^{*}$ & $41 / 3 b$ & Cattle & England & 1963 \\
\hline $\mathbf{S} 2334$ & $106 / 3 b$ & Man & England & 1963 \\
\hline S3350 & $130 / 3 b$ & Man & New Zealand & 1970 \\
\hline $\mathrm{S} 3403^{*}$ & $183 / 7 b$ & Man & England & 1955 \\
\hline S2696 & $22 / 9 b$ & Man & Venezuela & 1956 \\
\hline S3285 & $65 / 12$ bdh $x$ & Cattle & England & 1963 \\
\hline S2700* & $3 / 17 b$ & Turtle & Vietnam & 1956 \\
\hline S3104 & $9 / 17 b$ & Fertilizer & New Zealand & 1969 \\
\hline S3105 & $9 / 17 b$ & Fertilizer & New Zealand & 1969 \\
\hline S3164 & $9 / 17 b$ & Man & New Zealand & 1969 \\
\hline S3168 & $9 / 17 b$ & Man & New Zealand & 1969 \\
\hline S3170 & $9 / 17 b$ & Man & New Zealand & 1969 \\
\hline S3280 & $60 / 17 b$ & Unknown & Scotland & 1959 \\
\hline S2549 & $60 / 17 b$ & Man & New Zealand & 1964 \\
\hline S3106 & $61 / 17 \mathrm{~b}$ & Fertilizer & New Zealand & 1969 \\
\hline S1436 & $64 / 17 b$ & Sheep & New Zealand & 1962 \\
\hline S749 & $117 / 17 \mathrm{be}$ & Unknown & Sweden & Unknown \\
\hline S750 & $117 / 17 \mathrm{be}$ & Unknown & Sweden & Unknown \\
\hline S3117 & $3 / 17 \mathrm{bf}$ & Man & Mexico & 1969 \\
\hline $\mathbf{S} 2626^{*}$ & $10 / 17 b f$ & Man & Tunisia & 1956 \\
\hline $\mathrm{S} 2656$ & $9 / 17 \mathrm{bg}$ & Man & France & 1957 \\
\hline S2802 & $3 / 17 \mathrm{bj}$ & Duck & S. Carolina, U.S.A. & 1962 \\
\hline S6631* & $10 / 25 b$ & Man & England & 1958 \\
\hline S3180 & $66 / 25 b$ & Man & Germany & 1969 \\
\hline S3181* & $66 / 25 b$ & Man & Germany & 1969 \\
\hline $\mathrm{S} 2519^{*}$ & $67 / 25 b$ & Cattle & England & 1964 \\
\hline S3308 & $88 / 25 b$ & Man & England & 1963 \\
\hline S3311 & $91 / 25 b$ & Man & England & 1958 \\
\hline S3258* & $38 / 25 \mathrm{bcg}$ & Man & Canada & 1964 \\
\hline S2784* & $99 / 25 \mathrm{bhi}$ & Horse & Kentucky, U.S.A. & 1962 \\
\hline S1566* & $49 / 26 b$ & Pig & Indiana, U.S.A. & 1962 \\
\hline S3144 & $49 / 26 b$ & Man & Mexico & 1969 \\
\hline
\end{tabular}

* Strains most commonly tested as donors of fim.

both to transduce untypable strains and to select $\mathrm{Fim}^{+}$transductants from non-motile recipients (Old \& Duguid, 1971). The 258 strains had been isolated between 1947 and 1973 from man, nine other species of mammals, 13 species of birds and some inanimate sources in 19 countries on five continents. They included representatives of 4 primary and 22 full biotypes and 27 phage types (see Anderson et al., 1978). Three non-motile strains, S580, S635 and S1723, were tested as donors; their motile variants, S580M, S6356 and S1723M (Old \& Duguid, 1971), were tested as recipients.

(iii) Non-FIRN Fim- biogroup. We tested 39 of the 44 wild-type non-FIRN Fim- strains of Duguid et al. (1975), excluding one strain that was phage-untypable, two that gave rise to spontaneous Fim ${ }^{+}$mutants and two now reclassified as FIRN-like (Table 2).

(iv) FIRN-like biogroup. The two wild-type $\mathrm{Fim}^{-} \mathrm{Inl}^{+} \mathrm{Rha}^{-} \mathrm{Bxyl}^{-}$strains (Table 1) differed from FIRN only by being $\mathrm{Inl}^{+}$.

Induced Fim $^{-}$mutants. The Fim ${ }^{-}$character was not wild-type in two Fim- ${ }^{-}$Rha- $^{-}$Fla- cultures, LT2-D461 and LT2-D464, derived by Dr Jean Dubnau from an ade pro ilv streptomycin-resistant line of strain LT2 after treatment with ethyl methanesulphonate (Table 1). Because they were non-motile (Fla-), they were used only as donors. Both behaved similarly and their results are given as for a single strain.

Culture media. Nutrient broth (pH 7·3) was $1 \%$ (w/v) Oxoid bacteriological peptone, $1 \%$ (w/v) Oxoid 
Lab-Lemco beef extract and $0.5 \%(\mathrm{w} / \mathrm{v}) \mathrm{NaCl}$, or Oxoid Nutrient Broth no. 2, used in 8 to $10 \mathrm{ml}$ volumes in test tubes $(150 \times 15 \mathrm{~mm})$ stoppered with cotton-wool. Nutrient agar plates and slants contained Oxoid Nutrient Agar (pH 7.0).

Biotyping and the determination of transduced characters. These were done by the methods of Duguid et al. (1975).

Examination for fimbriae. Strains were examined for their ability to form type-1 fimbriae in serial broth cultures incubated for 48 to $96 \mathrm{~h}$ at $37^{\circ} \mathrm{C}$ under aerobic and static conditions (Duguid et al., 1966). One culture of each series was examined with the electron microscope and all cultures were tested for haemagglutinating activity in a rocked tile test in which the centrifuged deposit of bacteria was mixed for 20 min with $2 \%(\mathrm{v} / \mathrm{v})$ guinea-pig or horse red blood cells in saline. Agglutination of the red blood cells, and its inhibition in a parallel test containing $0.5 \%(\mathrm{w} / \mathrm{v}) \mathrm{D}$-mannose, indicated the presence of type- 1 fimbriae. The Fim- status of strains was proved in two series of six successive cultures. Scanty non-haemagglutinating (type-2) fimbriae in eight non-FIRN Fim- strains (Duguid et al., 1975) did not affect the results.

Donor phages. Phage P22 (Zinder \& Lederberg, 1952) was propagated on the donor strains of S. typhimurium. The strains most commonly used as donors are detailed in Table 1 . The lysates (usually $5 \times 10^{9}$ to $50 \times 10^{9}$ phages $\mathrm{ml}^{-1}$ ) were titrated and preserved by the methods of Old \& Duguid (1971) and their freedom from viable donor bacteria was confirmed before each experiment.

Of the 258 FIRN strains, 93 belonged to phage type 14 . They carried a phage related to P22 and generally did not support the free propagation of P22. Lysates of moderate titre $\left(10^{8}\right.$ or $10^{9}$ phages $\left.\mathrm{ml}^{-1}\right)$ were obtained from seven of these strains, perhaps because of variation after phage typing, and were used occasionally as donor phages. Some of the other 32 FIRN strains tested as donors are listed in Table 1.

Transduction of Fim. The methods of Old \& Duguid (1971) were used. Mixtures containing 1 to 5 phages per recipient bacterium (about $10^{8}$ bacteria $\mathrm{ml}^{-1}$ ) were cultured and subcultured once for 48 to $96 \mathrm{~h}$ at $37{ }^{\circ} \mathrm{C}$ in aerobic and static tubes of broth. Any culture that was haemagglutinating was plated on nutrient agar and the resulting single colonies were subcultured for $48 \mathrm{~h}$ in separate tubes of broth to isolate pure haemagglutinating cultures. One haemagglutinating clone from each transduction was tested for agglutination by $S$. typhimurium (O4) antiserum and for fermentation of inositol and rhamnose. Some clones were fully biotyped and examined with the electron microscope.

In each experiment, the recipient bacteria were tested in 'no-phage' control cultures to confirm that they did not give spontaneous Fim' ${ }^{+}$mutants. 'Homologous-phage' tests confirmed that self-crosses of the recipient strain did not generate $\mathrm{Fim}^{+}$progeny. Control mixtures of recipient bacteria and donor phage from the Fim $^{+}$strain LT2-497 were included in all experiments in which Fim ${ }^{-}$recipients were crossed with Fim $^{-}$donors. All the Fim ${ }^{-}$strains that were motile and phage-typable were tested as recipients.

\section{RESULTS}

The aggregated results of the transduction and 'no-phage' control tests with the different biogroups of donor and recipient strains of $S$. typhimurium are given in Table 3 . The proportion of tests, donor strains, recipient strains and combinations of strains crossed that gave $\mathrm{Fim}^{+}$recombinants is shown for each class of biogroup cross. That the Fim ${ }^{+}$ bacteria were recombinants is clear from the finding that there were no Fim ${ }^{+}$mutant bacteria in any of the no-phage and homologous-phage control cultures of the recipient Fim $^{-}$strains. Seven of the 39 non-FIRN Fim ${ }^{-}$strains had previously given spontaneous $\mathrm{Fim}^{+}$mutants during serial culture in broth (Duguid et al., 1975), but at a frequency much too low to account for the positive results in the present transduction experiments.

\section{Transduction from $\mathrm{Fim}^{+}$donors to $\mathrm{Fim}^{-}$recipients}

The results show that phage propagated on Fim ${ }^{+}$donor strains produced Fim ${ }^{+}$recombinants from most wild-type Fim $^{-}$recipient strains. Fim ${ }^{+}$recombinants were obtained from 32 of 37 motile non-FIRN Fim- ${ }^{-}, 257$ of 258 FIRN and both FIRN-like recipient strains (Table 3). Strain LT2-497 gave Fim ${ }^{+}$recombinants with 289 of the 291 Fim- recipients $^{-}$ that were successfully transduced by any $\mathrm{Fim}^{+}$donor and was a very competent donor of fim. It gave positive results in 125/552 tests with non-FIRN Fim-, 659/2160 with FIRN and 23/38 with FIRN-like recipients. All but one of the other $21 \mathrm{Fim}^{+}$strains tested as donors were also competent. 
Table 3. Transduction of fimbriation between donor and recipient strains of different biogroups of Salmonella typhimurium

In tests in which the donor and recipient strains belonged to the same biogroup, different strains were used as donor and recipient. The number of 'pairs' of strains crossed was the number of combinations of different strains, regardless of which was donor and which was recipient, for example, transductions from strain A to strain B and those from strain B to strain A were counted as for a single 'pair' crossed.

No. of tests, donors, recipients or pairs giving $\mathrm{Fim}^{+}$bacteria/no. tested, in crosses with Fim ${ }^{-}$ recipient strains of biogroup:

\begin{tabular}{|c|c|c|c|c|}
\hline \multirow[b]{2}{*}{ Donor strain biogroup } & \multirow{2}{*}{$\begin{array}{l}\text { Results } \\
\text { given for: }\end{array}$} & \\
\hline & & Non-FIRN Fim & FIRN & FIRN-like \\
\hline Fim $^{+}$ & $\begin{array}{l}\text { Tests } \\
\text { Donors } \\
\text { Recipients } \\
\text { Pairs }\end{array}$ & $\begin{array}{c}161 / 797 \\
6 / 11 \\
32 / 37 \\
46 / 79\end{array}$ & $\begin{array}{c}803 / 2913 \\
21 / 22 \\
257 / 258 \\
326 / 451\end{array}$ & $\begin{array}{c}28 / 54 \\
2 / 2 \\
2 / 2 \\
4 / 4\end{array}$ \\
\hline Induced Fim- mutant & $\begin{array}{l}\text { Tests } \\
\text { Donors } \\
\text { Recipients } \\
\text { Pairs }\end{array}$ & $\begin{array}{c}40 / 268 \\
1 / 1 \\
19 / 37 \\
19 / 37\end{array}$ & $\begin{array}{c}217 / 411 \\
1 / 1 \\
134 / 136 \\
134 / 136\end{array}$ & $\begin{array}{c}20 / 42 \\
1 / 1 \\
2 / 2 \\
2 / 2\end{array}$ \\
\hline Non-FIRN Fim- & $\begin{array}{l}\text { Tests } \\
\text { Donors } \\
\text { Recipients } \\
\text { Pairs }\end{array}$ & $\begin{array}{l}98 / 1427 \\
16 / 20 \\
15 / 37 \\
41 / 292\end{array}$ & $\begin{array}{l}72 / 2218 \\
18 / 33 \\
25 / 75 \\
50 / 755\end{array}$ & $\begin{array}{l}8 / 24 \\
1 / 2 \\
2 / 2 \\
2 / 4\end{array}$ \\
\hline FIRN & $\begin{array}{l}\text { Tests } \\
\text { Donors } \\
\text { Recipients } \\
\text { Pairs }\end{array}$ & $\begin{array}{l}66 / 763 \\
16 / 36 \\
11 / 37 \\
26 / 202\end{array}$ & $\begin{array}{l}0 / 1660 \\
0 / 39 \\
0 / 258 \\
0 / 1016\end{array}$ & $\begin{array}{l}0 / 353 \\
0 / 21 \\
0 / 2 \\
0 / 39\end{array}$ \\
\hline FIRN-like & $\begin{array}{l}\text { Tests } \\
\text { Donors } \\
\text { Recipients } \\
\text { Pairs }\end{array}$ & $\begin{array}{c}18 / 70 \\
2 / 2 \\
3 / 17 \\
5 / 34\end{array}$ & $\begin{array}{l}0 / 232 \\
0 / 2 \\
0 / 6 \\
0 / 12\end{array}$ & $\begin{array}{l}0 / 113 \\
0 / 2 \\
0 / 2 \\
0 / 1\end{array}$ \\
\hline None (no-phage control) & $\begin{array}{l}\text { Tests } \\
\text { Recipients }\end{array}$ & $\begin{array}{l}0 / 808 \\
0 / 37\end{array}$ & $\begin{array}{l}0 / 1951 \\
0 / 258\end{array}$ & $\begin{array}{l}0 / 86 \\
0 / 2\end{array}$ \\
\hline
\end{tabular}

The Fim- recipients differed markedly in their susceptibility to transduction of fim. Most gave $\mathrm{Fim}^{+}$recombinants in about half of their tests with good donors but some were less susceptible, for example, FIRN strain S2804 gave Fim ${ }^{+}$recombinants with LT2-497 in only 1 of 101 tests and the non-FIRN Fim- strain S2334 did so in only 1 of 37 tests. One FIRN strain, S2792, and five non-FIRN Fim ${ }^{-}$strains did not give a Fim ${ }^{+}$recombinant in any of many tests with Fim ${ }^{+}$donors.

It was not possible to determine the proportion of $\mathrm{Fim}^{+}$transductants originally produced in the mixture of donor phage and recipient bacteria, because the Fim ${ }^{+}$bacteria were detected by haemagglutination only after selective outgrowth in broth for $48 \mathrm{~h}$, by which time they had formed between 5 and $40 \%$ of the bacterial population. Probably, however, the frequency of transduction was low, for negative results were obtained in some tests made with most competent pairs of donor and recipient strains.

\section{Transduction from $\mathrm{Fim}^{-}$donors to $\mathrm{Fim}^{-}$recipients}

The wild-type Fim ${ }^{-}$strains in which the fim gene was in a mutated form were less effective donors of fim than the $\mathrm{Fim}^{+}$strains. Table 3 shows that $\mathrm{Fim}^{+}$recombinants were obtained in only 66 of 763 tests of FIRN donors with non-FIRN Fim ${ }^{-}$recipients and 72 of 2218 
tests of non-FIRN Fim ${ }^{-}$donors with FIRN recipients, as compared with 161 of 797 and 803 of 2913 tests of Fim ${ }^{+}$donors with these two groups of recipients. The induced (Dubnau) Fim $^{-}$mutants, by contrast, were nearly as effective as the best Fim ${ }^{+}$donors with recipients of all wild-type Fim- biogroups (Table 3).

Non-FIRN Fim ${ }^{-} \times$non-FIRN Fim ${ }^{-}$crosses. Twenty of the 39 wild-type non-FIRN Fim ${ }^{-}$ strains, including the two that were non-motile, were tested as donors in crosses with one or more of the 37 motile non-FIRN Fim ${ }^{-}$strains as recipients. Fim ${ }^{+}$recombinants were obtained from 16 of the 20 donors, 15 of the 37 recipients and 41 of the 292 different pairs of strains crossed, in a total of 98 out of 1427 tests.

Non-FIRN Fim ${ }^{-} \times$FIRN crosses. Fim ${ }^{+}$recombinants were obtained in 138 of 2981 tests of crosses between strains of these two Fim- biogroups. They were given by 23 of the 39 non-FIRN Fim ${ }^{-}$strains, including 18 of 33 tested as donors and 11 of 37 tested as recipients. Thirteen of the 16 non-FIRN Fim ${ }^{-}$strains that failed to give Fim ${ }^{+}$recombinants in crosses with FIRN strains had given Fim $^{+}$recombinants in crosses with Fim ${ }^{+}$donors and thus they were not generally insusceptible to transduction of fim.

FIRN $\times$ FIRN crosses. Fim ${ }^{+}$recombinants were not obtained in any of 1660 tests with 39 FIRN strains as donors and all 258 motile FIRN strains and variants as recipients, in which 1016 different combinations of strains were tested as donor-recipient pairs (Table 3). Specially numerous tests were made with those FIRN strains that had given Fim ${ }^{+}$recombinants as donors or recipients with non-FIRN Fim ${ }^{-}$strains so that the absence of Fim ${ }^{+}$ recombinants in the FIRN $\times$ FIRN crosses was significant.

FIRN-like strains. The two FIRN-like strains gave Fim ${ }^{+}$recombinants when crossed with Fim $^{+}$or non-FIRN Fim ${ }^{-}$strains, but not when crossed with one another or with any FIRN strain (Table 3), and so behaved like FIRN strains.

\section{Characters of the Fim ${ }^{+}$transductants}

The isolated clones of $\mathrm{Fim}^{+}$transductants always retained the other biotype characters of the recipient strain. Thus, the Fim ${ }^{+}$transductants from FIRN recipients crossed with a $\mathrm{Fim}^{+} \mathrm{Inl}^{+} \mathrm{Rha}^{+} \mathrm{Bxyl}^{+}$donor had the characters Fim ${ }^{+} \mathrm{Inl}^{-} \mathrm{Rha}^{-} \mathrm{Bxyl}^{-}$, a combination not found in naturally occurring strains (Duguid et al., 1975).

The Fim ${ }^{+}$transductant cultures studied with the electron microscope were seen to possess fimbriae; as their haemagglutinating activity was inhibited by mannose, these fimbriae were type-1. The transduced Fim ${ }^{+}$character was stable and Fim $^{-}$revertants were not encountered in numerous subcultures, although, like wild-type Fim $^{+}$strains, the transduced $\mathrm{Fim}^{+}$strains temporarily entered a largely non-fimbriate phase when grown on agar instead of in broth (Duguid et al., 1966).

\section{DISCUSSION}

Our results show that the ability to produce type- 1 fimbriae (Fim ${ }^{+}$) can be transduced from most Fim ${ }^{+}$strains of $S$. typhimurium as donors to most wild-type FIRN and non-FIRN Fim $^{-}$strains of $S$. typhimurium as recipients.

\section{Non-FIRN Fim- strains}

The finding that Fim ${ }^{+}$recombinants were produced in many crosses between different wild-type strains in the non-FIRN Fim ${ }^{-}$biogroup was evidence that the intragenic sites of the fim mutations were different in the donor and recipient strains of each fertile cross. We could not determine how many independent fim mutations there were among the 39 nonFIRN Fim- strains, because we were unable to make a large number of tests on every possible combination of these strains. The positive results showed that there were at least four different fim mutations in different strains of the biogroup. These were represented in 
strains S1566, S2784, S3403 and S6631, each of which gave Fim ${ }^{+}$recombinants in crosses with each of the other three. Probably, however, there were other fim mutations in the biogroup, for most of the 39 strains differed from the others in phage type, biotype and source (Table 2) and probably arose independently by fim mutations in different ancestral $\mathrm{Fim}^{+}$bacteria.

The only non-FIRN Fim ${ }^{-}$strains that appeared to have a common origin with some other members of the biogroup were five of phage type 9 biotype $17 \mathrm{~b}$ and one of phage type 61 biotype 17b isolated in New Zealand in 1969, two of phage type 29 biotype $1 \mathrm{bf}$ isolated in Scotland in 1971, and two of phage type 66 biotype 25b isolated in Germany in 1969. $\mathrm{Fim}^{+}$recombinants were not obtained in crosses between pairs of strains within any of these three groups. The rarity of strains in the non-FIRN Fim- biogroup suggests that none established itself as an epidemic strain.

The sites of the fim mutations in the FIRN strains and the induced (Dubnau) Fim ${ }^{-}$ mutants, which differed from one another, also differed from those in the transducible non-FIRN strains, for $\mathrm{Fim}^{+}$recombinants were commonly obtained in crosses between members of these three different groups.

\section{FIRN strains}

Although FIRN strains gave Fim ${ }^{+}$recombinants in crosses with many strains of the non-FIRN Fim- biogroup and Fim- Dubnau strains, showing that the sites of their fim mutations differed from those of the latter groups, they did not give $\mathrm{Fim}^{+}$recombinants in crosses among themselves. This observation suggests that their fim mutations are located at identical sites. The possibility that they are located at different sites that overlap, or are too close for recombination at a detectable frequency, is unlikely in view of the finding that independently originating fim mutations in the small non-FIRN Fim ${ }^{-}$group are not overlapping or closely situated. The most likely explanation of this apparent genetic homogeneity of FIRN strains is that all have descended from the same ancestral Fimmutant bacterium.

Further evidence that the FIRN strains have a common evolutionary origin is provided by the observations suggesting that they are also homogeneous in the sites of their rha and inl mutations. Morgenroth \& Duguid (1968) examined 23 FIRN strains for transduction of $r h a$ and found that $\mathrm{Rha}^{+}$recombinants were not produced in any cross between different FIRN strains, although they were produced in most crosses between FIRN strains and non-FIRN Rha ${ }^{-}$strains of primary biotype 7 . Similar tests demonstrated the absence of $\mathrm{Rha}^{+}$recombinants in crosses between different pairs of a further 110 FIRN strains (Old, 1963). Preliminary experiments on the transduction of inl have yielded Inl $^{+}$recombinants from most crosses of FIRN strains as recipients with non-FIRN Inl- strains of biotype 9 as donors but not in any of many crosses of different pairs of FIRN strains (D. C. Old, unpublished results).

Since its origin, the FIRN clone must have spread throughout the world and diversified by genetic variation into the 22 full biotypes and 27 phage types now recognized. Most biotype characters occasionally undergo spontaneous change in the laboratory and during epidemic spread of the bacteria in their hosts (Duguid et al., 1975; Anderson et al., 1978) so that the diversification of FIRN biotypes could have been fairly rapid.

The archetypal $S$. typhimurium was probably a $\mathrm{Fim}^{+} \mathrm{Inl}^{+} \mathrm{Rha}^{+} \mathrm{Bxyl}^{+}$strain of biotype 1a, the commonest biotype and one in which the genes for all 15 biotyping characters are in their unmutated forms. This archetypal strain probably gave rise by a $x y l$ mutation to a strain of biotype 17a, which gave rise by an inl mutation to a strain of biotype 25a, which in turn gave rise by successive $r h a$ and fim mutations to the ancestral FIRN strain of biotype $29 \mathrm{~b}$. It is from this proposed archetypal FIRN strain that all the other FIRN strains probably descended. The suggested origin of these common biotypes is shown in Fig. 1, modified from Duguid et al. (1975). 
Biotype derivations

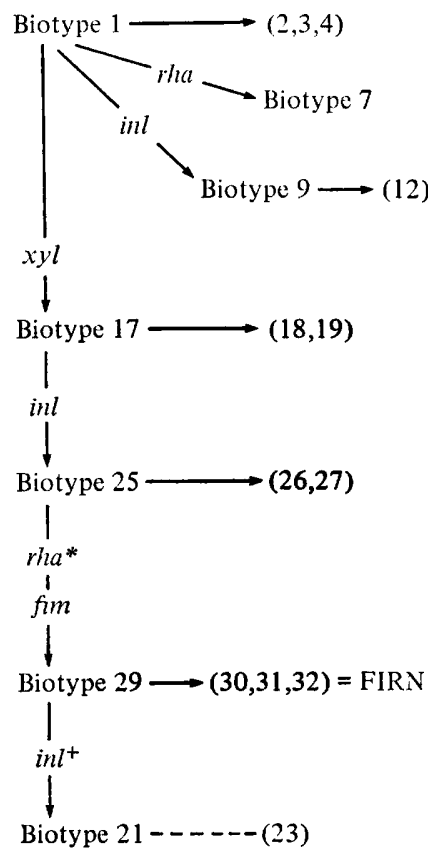

Biotype characters

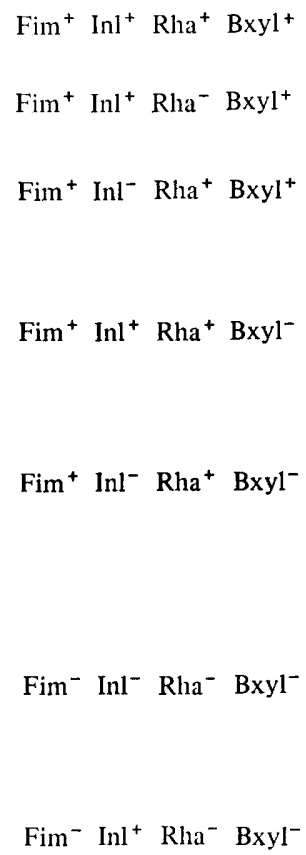

Fig. 1. Possible mutational routes whereby the known primary biotypes of Salmonella typhimurium evolved from the presumed archetypal biotype 1 . Shown in parentheses are the D-tartrate-negative $(3,19,23,27,31)$, meso-tartrate-negative $(2,18,26,30)$ and $\mathrm{D}$-tartrate-negative, meso-tartratenegative $(4,12,32)$ biotypes derived from the major biotypes, which are D-tartrate-positive, meso-tartrate-positive.

* Probably there were two successive mutations in rha: $\mathrm{Rha}^{+}$to $\mathrm{Rha}^{\text {w }}$ and $\mathrm{Rha}^{\text {w }}$ to $\mathrm{Rha}^{-}$ (Morgenroth \& Duguid, 1968).

FIRN strains show occasional spontaneous back mutations to $\mathrm{Inl}^{+}, \mathrm{Rha}^{+}$or $\mathrm{Bxyl}^{+}$ forms and, after mutagenesis, to a Fim $^{+}$form (Duguid et al., 1975). Moreover, from a $D$-tartrate-negative, meso-tartrate-negative strain of biotype $32 \mathrm{~b}$, we have derived a culture of biotype $1 \mathrm{~b}$ by the isolation of spontaneous mutants that were, successively, D-tartratepositive, meso-tartrate-positive, and capable of utilizing as sole carbon sources, rhamnose, inositol and xylose. From this biotype $1 \mathrm{~b}$ culture, we derived after mutagenesis a fimbriate line of biotype 1a. Thus, by artificial reversal of the presumed evolutionary pathway, we have demonstrated that FIRN strains possess in a mutated form, the genes that confer $\mathrm{Fim}^{+}, \mathrm{Inl}^{+}, \mathrm{Rha}^{+}, \mathrm{Bxyl}^{+}$and other characters of the archetypal biotype 1a.

The evolutionary sequence described would explain the results of the transductions of fim and $r h a$, but further experiments are needed to show whether the inl mutation is the same in FIRN and biotype 25a strains, and whether the $x y l$ mutation is the same in FIRN, biotype $25 \mathrm{a}$ and biotype 17a strains. The observation (Old, 1972) that most strains in primary biotypes $25,26,29,30,31$ and 32 have a temperature-sensitive inositol phenotype enabling them to ferment inositol only at temperatures below $37{ }^{\circ} \mathrm{C}$ is at least suggestive that the inl mutation is the same in these different biotypes.

\section{FIRN-like strains}

The absence of Fim ${ }^{+}$recombinants and $\mathrm{Rha}^{+}$recombinants in any cross between FIRN and FIRN-like strains suggests that the respective sites of the fim and $r h a$ mutations are the same in the two biogroups and supports the view of Duguid et al. (1975) that the rare 
FIRN-like strains are Inl ${ }^{+}$back-mutants from FIRN strains. Further evidence of this proposed relationship is seen from the phage types of the FIRN-like strains, since all our other strains of the phage types 13 (43 strains) and 160 (17 strains) have been FIRN.

The two FIRN-like strains were isolated in Britain in 1958 and 1963. They were the only strains of primary biotypes 21 and 23 in the series of 2030 strains, about half of which were isolated in Britain after 1958. Apparently, therefore, they did not establish themselves as epidemic strains. Whether their disappearance was accidental or due to the $\mathrm{Fim}^{-} \mathrm{Inl}^{+} \mathrm{Rha}^{-}$ $\mathrm{Bxyl}^{-}$combination of characters being in some way detrimental to their parasitic competence is unknown.

The transduction method of determining genetic relationships in wild-type strains has thus been helpful in tracing parts of the genealogy of the biotypes of $S$. typhimurium. It was first used for this purpose in studies of nicotinamide-requiring strains of $S$. typhimurium (phage type 135, biotype 25x) by B. A. D. Stocker and J. B. Edgar in 1959 (see Morgenroth \& Duguid, 1968; Anderson et al., 1978). It should also be applicable in elucidating the recent evolutionary history of other groups of bacteria.

\section{REFERENCES}

Anderson, E.S., WARD, L. R., DE SAXE, M. J. \& DE SA, J. D. H. (1977). Bacteriophage-typing designations of Salmonella typhimurium. Journal of Hygiene 78, 297-300.

ANDERSon, E. S., WARd, L. R., DE SAXe, M. J., OLD, D. C., Barker, R. \& Duguid, J.P. (1978). Correlation of phage type, biotype and source in strains of Salmonella typhimurium. Journal of Hygiene 81, 203-218.

BoyD, J.S. K. (1956). Immunity of lysogenic bacteria. Nature, London 178, 141.

Demerec, M., Moser, H., Hemmerly, J., Blomstrand, I., Demerec, Z. E., Fitzgerald, P. L., Glover, S. W., Hanson, J. F., Nielson, F. J. \& YURA, T. (1954). Bacterial genetics, I. Yearbook of the Carnegie Institution of Washington 53, 225-241.

Duguid, J. P., Old, D. C. \& Hume, V. B. M. (1962). Transduction of fimbriation and rhamnose fermentation characters in Salmonella typhimurium. Heredity 17, 301-302.

Duguid, J.P., Anderson, E. S. \& Campbell, I. (1966). Fimbriae and adhesive properties in salmonellae. Journal of Pathology and Bacteriology 92, 107-138.

Duguid, J. P., Anderson, E. S., Alfredsson, G. A., BARKER, R. \& OLD, D. C. (1975). A new biotyping scheme for Salmonella typhimurium and its phylogenetic significance. Journal of Medical Microbiology 8, 149-166.

Friewer, F. I. \& Leirson, E. (1952). Non-motile flagellated variants of Salmonella typhimurium. Journal of Pathology and Bacteriology 64, 223-224.
Hartman, P. E. (1956). Genetic studies with bacteria. Publications of the Carnegie Institution of Washington, no. 612, 35-62.

LiLLEENGEN, K. (1948). Typing of Salmonella typhimurium by means of bacteriophage. Acta pathologica et microbiologica scandinavica, Supplement $77,1-125$.

Morgenroth, A. \& Duguid, J. P. (1968). Demonstration of different mutational sites controlling rhamnose fermentation in FIRN and non-FIRN rha- strains of Salmonella typhimurium: an essay in bacterial archaeology. Genetical Research 11, 151-169.

OLD, D. C. (1963). Fimbriation in enterobacteria. Ph.D. thesis, University of Edinburgh.

OLD, D.C. (1972). Temperature-dependent utilization of meso-inositol - a useful biotyping marker in the genealogy of Salmonella typhimurium. Journal of Bacteriology 112, 779-783.

Old, D.C. \& Duguid, J.P. (1970). Selective outgrowth of fimbriate bacteria in static liquid medium. Journal of Bacteriology 103, 447-456.

Old, D.C. \& DuguID, J.P. (1971). Selection of fimbriate transductants of Salmonella typhimurium dependent on motility. Journal of Bacteriology 107, 655-658.

SANDERSON, K. E. (1972). Linkage map of Salmonella typhimurium. Edition IV. Bacteriological Reviews 36, 558-586.

Zinder, N. D. \& LeDerberG, J. (1952). Genetic exchange in Salmonella. Journal of Bacteriology 64, 679-699. 